\title{
整 University
}

Michaelowa, K., Reinsberg, B. and Schneider, C. (2017) Multi-bi aid in European development assistance: the role of capacity constraints and member state politics. Development Policy Review, 35(4), pp. 513-530.

There may be differences between this version and the published version. You are advised to consult the publisher's version if you wish to cite from it.

This is the peer reviewed version of the following article Michaelowa, K., Reinsberg, B. and Schneider, C. (2017) Multi-bi aid in European development assistance: the role of capacity constraints and member state politics. Development Policy Review, 35(4), pp. 513-530, which has been published in final form at http://dx.doi.org/10.1111/dpr.12193. This article may be used for non-commercial purposes in accordance with Wiley Terms and Conditions for Self-Archiving.

http://eprints.gla.ac.uk/172867/

Deposited on: 5 November 2018

Enlighten - Research publications by members of the University of Glasgow http://eprints.gla.ac.uk 


\title{
Multi-bi Aid in European Development Assistance: The Role of Capacity Constraints and Member State Politics
}

\author{
Katharina Michaelowa, Bernhard Reinsberg and Christina Schneider*
}

\begin{abstract}
We analyse the patterns of multi-bi aid in the European Union. Using newly available multi-bi aid data and a large number of staff interviews at the European Commission, the World Bank and bilateral donors, we draw three conclusions. First, the Commission's capacity constraints and lack of specific expertise have prevented it from becoming an important host of trust funds like other international development organizations. Second, the same capacity constraints can generally explain its extensive participation in trust funds at other international development organizations. In the case of large global funds, however, Commission participation often reflects the outcome of member state politics. Third, once the Commission delegates its aid to multilateral agencies, it does not impose strong substantive earmarking, but requires a high level of legal and administrative controls.
\end{abstract}

Key words: European Union, multilateral agencies, delegation, multi-bi aid, earmarking

Author affiliations: Katharina Michaelowa, Bernhard Reinsberg (University of Zurich, Center for Comparative and International Studies, CIS), and Christina Schneider (University of California, San Diego). This article complements another paper on EU development assistance written in the context of the research program 'The Proliferation of Multilateral Funds: Explaining the shift towards multi-bi aid and related institutions', which contains a more general technical analysis (Michaelowa et al., 2015). We thank our interview partners from the European Commission for their time. In addition, we gratefully acknowledge funding from the Swiss Network for International Studies (SNIS). 


\section{Introduction}

Since the early 1990s, donor governments have increasingly channelled their development assistance through trust funds hosted at international development organizations (IDOs). ${ }^{1}$ They did so on a voluntary basis (i.e., without long-term international commitments) and without generally dismissing their rights to determine the concrete project specification or geographical or sectoral allocation, which they enforced through various degrees of earmarking (Reinsberg et al., 2015a; Graham, 2015). To many donors, this so-called 'multi-bi aid', which is situated somewhere in between bilateral and multilateral assistance, appears to be an ideal strategy to implement the requirements of the Paris Declaration calling for donor cooperation and harmonization (Barakat, 2009: 108; Woods, 2005: 394; Barakat et al., 2012: 2f.), and as a useful instrument to pool resources for the funding of global public goods that have received increasing attention over time (Heimans, 2004; IEG, 2011).

The European Union (EU) is a particularly interesting donor to examine in the multi-bi aid context. First, it simultaneously plays a role as a bilateral donor and as an IDO. It can hence be examined both on the demand and on the supply side of multi-bi aid. As a bilateral donor, it may make use of trust funds located at other IDOs, and as an IDO, it can be the host of trust funds for development assistance provided by other bilateral donors. Second, the EU already represents a sub-group of bilateral donors, and is supposed to ensure coordination and harmonization among its members. If individual EU members want to coordinate with other donors, they can directly become members of trust funds at other IDOs. If the EU itself also becomes a member of such funds, this involves double-delegation (and related transaction costs), which runs against the spirit of the complementarity principle included in the EU's Code of Conduct (EC, 2007). Moreover, it calls into question whether the coordination and harmonization arguments for multi-bi aid truly reflect the central motivation of the EU to use trust funds. Third, within other IDOs, the EU is frequently identified as a particularly burdensome partner for multi-bi aid. It appears important to examine the reasons for such assessments and how they can be reconciled with the EU's willingness to participate in those trust funds in the first place. Finally, with an aid volume of over 16 billion dollars in 2014 (about 25\% of its individual members' development assistance), the EU institutions have emerged as the single largest multilateral donor and one of the largest bilateral donors on the global scene (OECD, 2015). ${ }^{2}$ Given the sheer size of its interventions it becomes interesting to look at its strategy, politics, and the resulting efficiency of its operations.

Along with Michaelowa et al. (2015) this article is an early analysis of the politics of multi-bi aid in the EU. It focuses on the presentation of the complex economic and political considerations that determine the European Commission (EC)'s strategic choices. In other articles of this special edition, these choices appear strongly constrained by the EU's collective action problem. This appears to be less relevant in the context of multi-bi aid. To some extent, multi-bi aid can even serve as a means to overcome collective action problems, an issue that will be highlighted below.

Section 2 presents some historical data on the EU institutions' involvement in multi-bi aid, and

\footnotetext{
As compared to Reinsberg et al. (2015), who distinguish between organizations with and without implementing capacity, we use the term IDO more generally here for any type of international organization engaged in the area of development.

2 In 2011 and 2012, regarding their disbursements of Official Development Assistance (ODA), the EU institutions ranked second directly after the United States. In 2014, the United Kingdom and Germany ranked second and third.
} 
discusses the puzzles we face when examining this evidence. Section 3 provides an empirical analysis drawing on information from interviews with officials at the EC, at other IDOs and in bilateral donor agencies. This information is triangulated with evidence from official reports, and with statistical evidence that is mostly based on a new dataset focusing on multi-bi aid, compiled by Eichenauer and Reinsberg (2016). Section 4 discusses the results and concludes.

\section{Some empirical evidence on the use of multi-bi aid}

EU members provide about $17 \%$ of their foreign aid resources through one of the three EU channels relevant for development aid: the common EU budget, the European Development Fund (EDF) and the European Investment Bank (EIB). Except for the EDF, where contributions are voluntary and renegotiated every five years, they are calculated on the basis of gross domestic product (GDP) and are mandatory for all members. While the EU receives member country contributions, it is itself often considered as a bilateral donor, and can again decide between different channels of aid allocation including multi-bi aid. The concessional side of its development programmes has been managed and implemented largely by the Commission. ${ }^{4}$ For simplicity, we will always refer to the EC when we discuss multi-bi aid given through the European institutions in order to distinguish it from bilateral EU member aid, even though technically EU governments decide about the EU's foreign aid resources through the EDF Committee, the Council of Ministers and other intergovernmental bodies in the EU.

Let us first consider the EC's use of multi-bi aid in its role as a bilateral donor. Figure 1 shows the development of its aid channelled through trust funds at other IDOs, both in absolute terms (panel 1) and relative to (pure) bilateral aid. The dashed lines show the development of multi-bi aid of the EU member countries for comparison. Ignoring the peak in 2005 that is due to the specific event of debt relief in the framework of the Heavily Indebted Poor Country Initiative (HIPC), we observe a relatively steady increase of multi-bi aid for EU members. This trend in bilateral EU aid did not translate into similar trends at the European level, where the level of multi-bi aid constantly stayed at very low levels until the mid-2000s.

From the mid-2000s onwards, the EC also started using trust funds hosted at other IDOs. Very quickly, the share of the EC's multi-bi aid increased to a similar proportion of bilateral aid as for other bilateral donors, and in 2012, at more than $25 \%$ of the EC's total aid, this share was even substantially higher than for EU member countries (about 13\%). Provisional data from the Development Assistance Committee (DAC) of the Organisation for Economic Co-operation and Development (OECD, 2015) indicate that the EC's multi-bi aid has further increased substantially in 2013.

4 See the introduction to this special edition for more information on EU aid, and Carbone (2007) for an excellent and comprehensive overview. 


\section{Figure 1: The development of multi-bi aid}
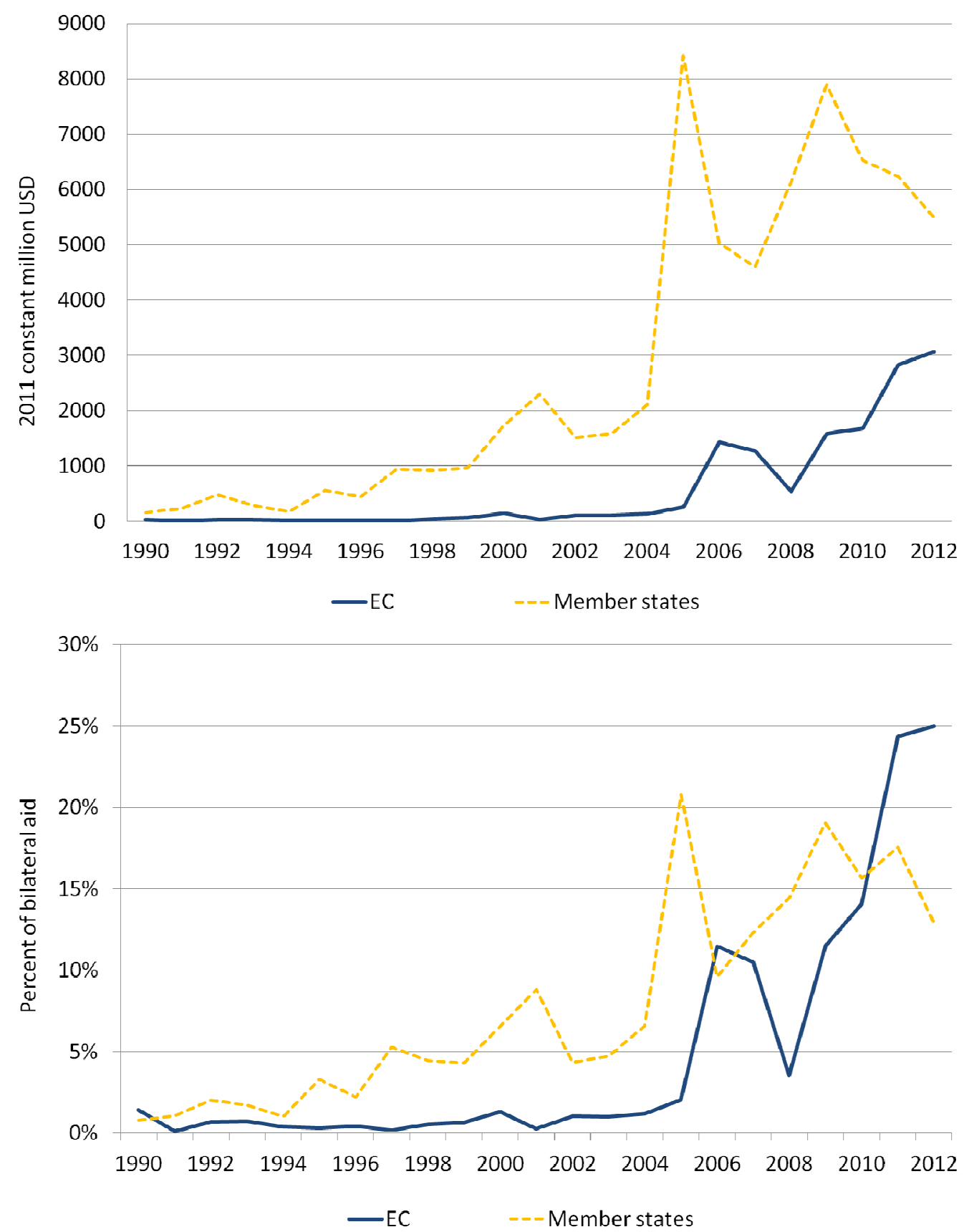

Data source: Eichenauer and Reinsberg (2016).

At the same time, the EC did not seize the opportunity to generate own trust funds and thereby collect additional funding by like-minded donors (sub-sets of member countries) for specific fields of intervention. While other IDOs administer hundreds of such funds, and the related financial volume is often greater than the core funding of these institutions (see Reinsberg et al., 2015a), the EC came up with its very first 'Union Trust Funds', the EU Trust Fund for the Central African Republic - a stabilization and reconstruction fund, supported by contributions from France, Germany and the 
Netherlands - and the MADAD Fund ${ }^{5}$ in response to the Syrian crisis, with initial contributions from Italy and Germany, only in 2014 (EC, 2015). ${ }^{6}$

This reluctance to set up its own trust funds is surprising. Would the EU not be an ideal institution to help some of its members to coordinate when they are willing to move forward on certain issues? Should the EC not have incentives to generate additional inflows of funding that would allow it to expand its field of activities? And why are member countries willing to contribute to the EC if the EC simply channels these funds through IDOs to which the member countries could have contributed bilaterally? Why are they willing to accept the transaction cost related to double-delegation (the other IDOs often charge considerable fees for their services)? A simple answer could be the EC's capacity constraints. But if channelling aid through other IDOs is a means of reducing the EC's own workload, why is the EC then simultaneously known for formulating a number of burdensome requirements, micromanaging the work of these other IDOs?

We answer these questions one by one based on rich evidence from a large number of interviews in Brussels, at other IDOs, and with aid agency staff of EU member countries. Our Brussels-based interviews covered the EC, notably the Directorates-General for International Cooperation and Development (DEVCO/EuropeAid), for Humanitarian Aid and Civil Protection (ECHO), as well as the European External Action Service (EEAS). We refer to these statements explicitly whenever they serve as the main basis for our argument, and systematically indicate opposing views in the few cases in which they occur. ${ }^{7}$

Information from these statements is then put in perspective by drawing on the general literature, agency reports and descriptive statistics based on a recent, comprehensive update of the OECD's Creditor Reporting System (CRS) data to include multi-bi aid (Eichenauer and Reinsberg, 2014; 2016) and other DAC data (OECD, 2015).

\section{Assessing the EU's engagement in multi-bi aid}

When assessing the reasons behind the surprising behaviour of the EC regarding the use of multi-bi aid, we consider both economic efficiency, and political or bureaucratic efficiency. While the former optimizes development outcomes, the latter optimizes the utility of different actors within the EU (member states, European Parliament, EC staff). Considerations about preserving the budget, the visibility of one's interventions and pleasing one's constituency fall in this category.

5 Madad means 'assistance' in Arabic.

6 Union Trust Funds are the first trust funds in which (a subset of) member states and other donors can support a special program administered by the EC. This distinguishes them from pure funding facilities like the EU-Africa Infrastructure Trust Fund (EU-AITF) managed by the EIB and jointly governed by EU member states and the EC, or the Africa Peace Facility, which is legally based on the Cotonou Agreement, financed from EDF and governed by the EDF committee.

7 Overall, we carried out 30 semi-structured interviews, partially group interviews, mostly at the EC and EEAS in Brussels in November 2014, and at the World Bank headquarters in Washington in summer 2013. In 2012, the World Bank was the single largest IDO with respect to multi-bi aid received from EU institutions. Some complementary interviews were held by telephone at a later stage. Overall, the opinion of about 40 officials is included in our analysis. In the following sections, we refer to individual interviews with specific numbers (e.g., I-1) to provide the reader with an idea of the number of separate interviews supporting a particular view. However, to protect the identity of our respondents, we do not reveal the corresponding names. The list of interviews (without attribution to the individual numbers in the text) can be obtained from the authors upon request. 


\subsection{Why has the EC been so reluctant to set up trust funds?}

While several of our interview partners at the EC proudly reported about the activities to set up the first Union Trust Fund in 2014 (e.g., I-29; I-30; I-31), nobody mentioned why it took so long for the EU to engage in such activities in the first place. We explore several potential explanations.

First, EU actors may simply be aware about the downsides of trust funds. These funds may distort the EC's programme priorities due to bypassing their standard decision-making procedures, raise concerns regarding the transparency of the EC's overall activities and the stringency of the monitoring and evaluation procedures applied, and increase aid fragmentation (see, for example, IEG, 2011; Tortora and Steensen, 2014; Reinsberg, 2016). However, when the EU finally launched its own trust funds, awareness about such general problems was much higher than before. Moreover, EC officials unanimously stated that Union Trust Funds would suffer much less from these problems. In fact, monitoring and evaluation was mentioned as a distinctive advantage of Union Trust Funds as compared to other IDOs (I-21), and as one of the reasons why the EC had eventually moved to setting up its own funds (I-19; I-20; I-26).

In a single case, an official also mentioned that a member state directly opposed the opening of a Union Trust Fund due to fear of competition. The statement refers to the proposal of a trust fund on energy, the very first Union Trust Fund that was proposed, but never put into place: 'The Germans killed it [...] because KfW [the German development bank] works a lot in this area.' (I-19). However, such direct competition should be a rare occurrence. While this particular case may have delayed the start of the EU's own trust funds by a few months, it cannot explain why nothing happened over decades. In any case, only a single respondent mentioned this issue.

Second, and more importantly, the sluggish adoption of Union Trust Funds may be related to legal constraints. Indeed, only in 2012 did member states adopt a new Financial Regulation that authorised the EC to set up and manage trust funds under an agreement concluded with other donors, including non-EU donors (EC, 2012). This was mentioned in several interviews (I-19; I-21). However, such regulations are endogenous to the influence of EU member countries. Our interviews suggest that for a long time, there was simply no demand for Union Trust Funds because EU members found their interests well addressed by trust funds at other IDOs. A major determinant of delegation to IDOs is their development expertise and capacity (Milner and Tingley, 2013; Schneider and Tobin, 2013; specifically on trust funds, see Reinsberg et al., 2015b). It seems that the EU member countries did not believe that the EC was as an IDO with a competitive edge in this regard. This would be in line with the criticism of the EC's development knowledge and experience in the DAC Peer Review (OECD, 2012). From this perspective, using trust funds at other IDOs was simply more economically efficient.

Third, for a long time, EC staff itself may not have been interested in setting up Union Trust Funds. Typically, bureaucratic actors push for new trust funds as a means to acquire more funding or to expand their remit (see, e.g., Michaelowa and Michaelowa, 2011). Between 1980 and 2012, however, budget expansion was no strong motive within EuropeAid. Financial means for development aid at the EU institutions increased by over $500 \%$ in real terms (OECD, 2015). Our interlocutors explicitly stated that money inflows were often so large that the existing staff faced difficulties in handling them efficiently 
(I-24). However, these considerations changed over time. Capacity substantially improved in the early 2000s (although it then again declined over time, see below), as shown by two metrics: the rise in administrative cost hints to greater investment in human resources (see Figure 3 and discussion below) and general staff numbers at the EC have increased. Moreover, experience from trust funds at other IDOs revealed that such funds could provide greater flexibility to middle management, given that the existing EU funds can only be used for specific priorities. In addition, the EC's top officials may use the funds to increase their weight in meetings with foreign ministers. Finally, many EC staff members realized that Union Trust Funds would enhance the EU's visibility as a global development player. Visibility is a serious concern mentioned by EC officials (I-19; I-20; I-21; I-22) and also by World Bank staff speculating on why the EC entered the trust fund business (I-9; I-14; I-15; I-16; I-17).

These bureaucratic and political advantages became clear during a period when conflict in Africa was increasingly recognized as a direct threat to Europe, and the humanitarian situation in the European neighbourhood became problematic due to the Syrian war. This created a window of opportunity for the creation of Union Trust Funds directed by the EC.

\subsection{Why has the EC been so strongly engaged in delegating to other IDOs?}

EC officials acknowledged that the strong evidence for double-delegation - from EU members to the EC and then to other IDOs - is puzzling, and that many observers question the efficiency of such arrangements. ${ }^{8}$ IDOs' management fees are not negligible. For instance, the (standard) fee charged to host a trust fund is 5\% of the relevant aid volume at the World Bank, and 7\% at the United Nations (I-22). EU member states can join these trust funds directly and thus avoid one layer of administration. Furthermore, the visibility of the EC within such trust funds is generally lower than for the EC's own bilateral aid. Finally, by delegating to other IDOs, the EC gives up its main function, in fact its raison d'être, to coordinate the activities of its member countries.

The reasons for delegation to other IDOs that were provided by different EC officials varied considerably. We can distinguish between arguments related to EC staff capacity and arguments related to member country politics. The latter were mentioned primarily (if not exclusively) in the context of large multi-donor trust funds, the so-called global funds. The former related to a wide variety of funds including single-donor trust funds with the EU institution as the sole contributor.

\subsubsection{Capacity constraints}

EC staff argued that in recent years, the EC faced increasing demands while witnessing its own capacities decline. According to our interview partners, additional issues emerged on the agenda, but at the same time EC staff numbers declined (I-22; I-24; I-29). In this context, delegation was considered very useful since it was tying up less administrative resources than 'direct management' by EC staff, and thus enabled the EU to 'do more with less' (I-22).

Since 'lack of capacity' is a standard complaint by bureaucracies, we cross-check the information from

8 From a purely legal perspective, as noted by one EC official, there is no 'double delegation' because the EC has own legal personality. However, from a principal-agent perspective, the EC is the agent of its member states and the IDO in turn, the agent of the EC. 
the interviews with other data. If capacities are scarce, the EC should generally delegate more aid, not only to IDOs. Figure 2 shows that this is true for EC aid channelled through the private sector. Moreover, we should expect a strong use of general budget support, which is directed towards recipient countries' priorities and hence does not require the development of concrete projects by the donor. This is equally confirmed by Figure 2. Indeed, the EC made a stronger use of general budget support than any other bilateral donor (OECD, 2015). It peaked in 2010 when the EU's general budget support was almost 2.5 times as high as that of the UK Department for International Development (DFID) - the second largest bilateral donor regarding budget support. In most recent years, however, the popularity of budget support declined among member states, which now underscore the problems of political capture (see Koch, this issue). This may have further accelerated the turn towards IDOs.

\section{Figure 2: Aid channels avoiding EC capacity constraints}

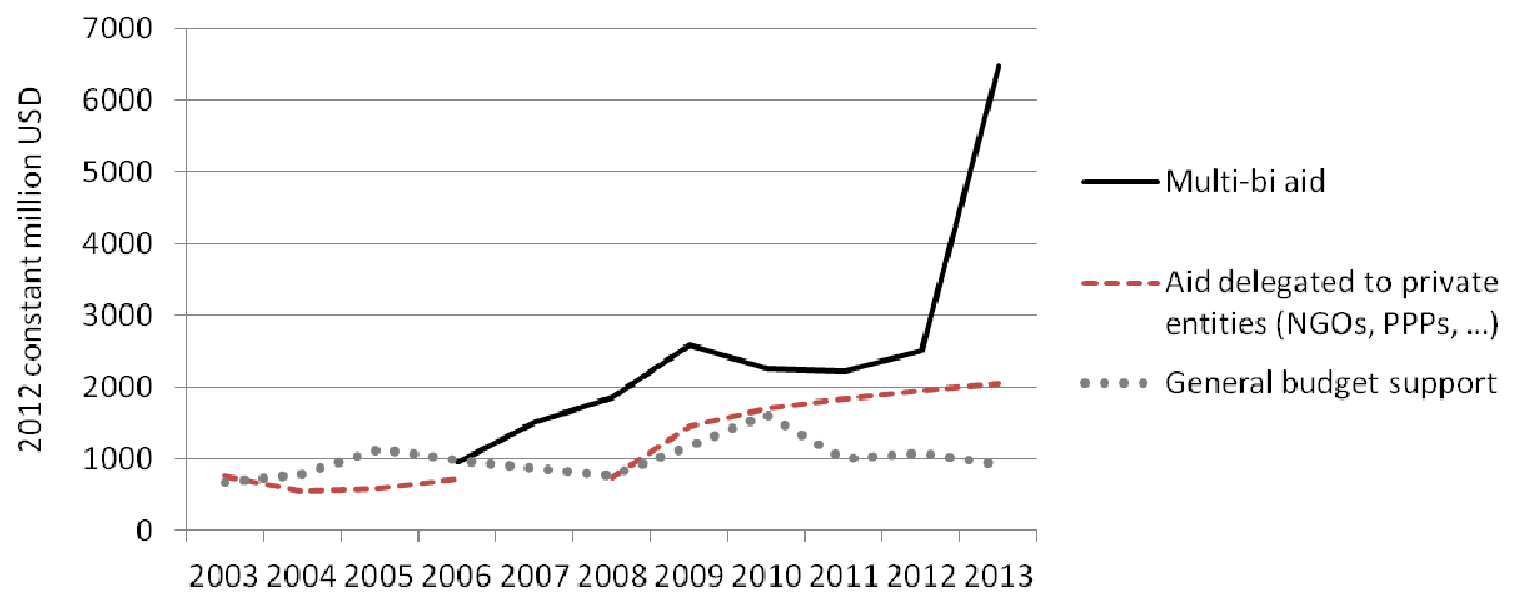

Data source: OECD (2015).

To more directly assess the validity of complaints about capacity constraints, we would have liked to examine EuropeAid staff numbers. Unfortunately, the EC does not provide these data. As a proxy, we consider the development of administrative cost as a share of the EC's overall bilateral aid budget (pure bilateral and multi-bi aid). Figure 3 shows the development of this share (in percentage terms) as compared to three major bilateral donors. It indicates that after a strong upward adjustment in the early 2000s, the EC's administrative costs slowly declined relative to the aid volume under its administration. The period of decline started just before the EC's move towards multi-bi aid. This is in line with the arguments we heard in our interviews.

Yet, administrative costs as a share of aid are about as high as for the three major bilateral donors, the United Kingdom, Germany and France. If they can be interpreted as an investment in staff capacity, despite the decline during the last few years, the EC should not be in such a bad situation. While the experience of some decline may explain the statements made in the interviews, taken these other countries as a benchmark, there should be no capacity problem, at least in quantitative terms.

However, capacity cannot only be measured in staff numbers and related expenses, but also in the way the existing capacities are managed or in subject-related expertise based on development specific 
knowledge and experience. These are areas in which the DAC Peer Review of the EC spotted great deficits. The review states that the lack of specific expertise was criticised by partners, member states and internal reviews alike (OECD, 2012: 20). The lack of expertise can be explained by the EC's human resource regulations in this area. Development experts can be hired on short-term contracts that may not exceed six years when employed in the headquarters in Brussels. In the field, they can remain in their positions for a longer period, but have no formal way to improve their position, so that retention is limited here, too.

\section{Figure 3: The development of administrative cost in percent of total bilateral aid*}

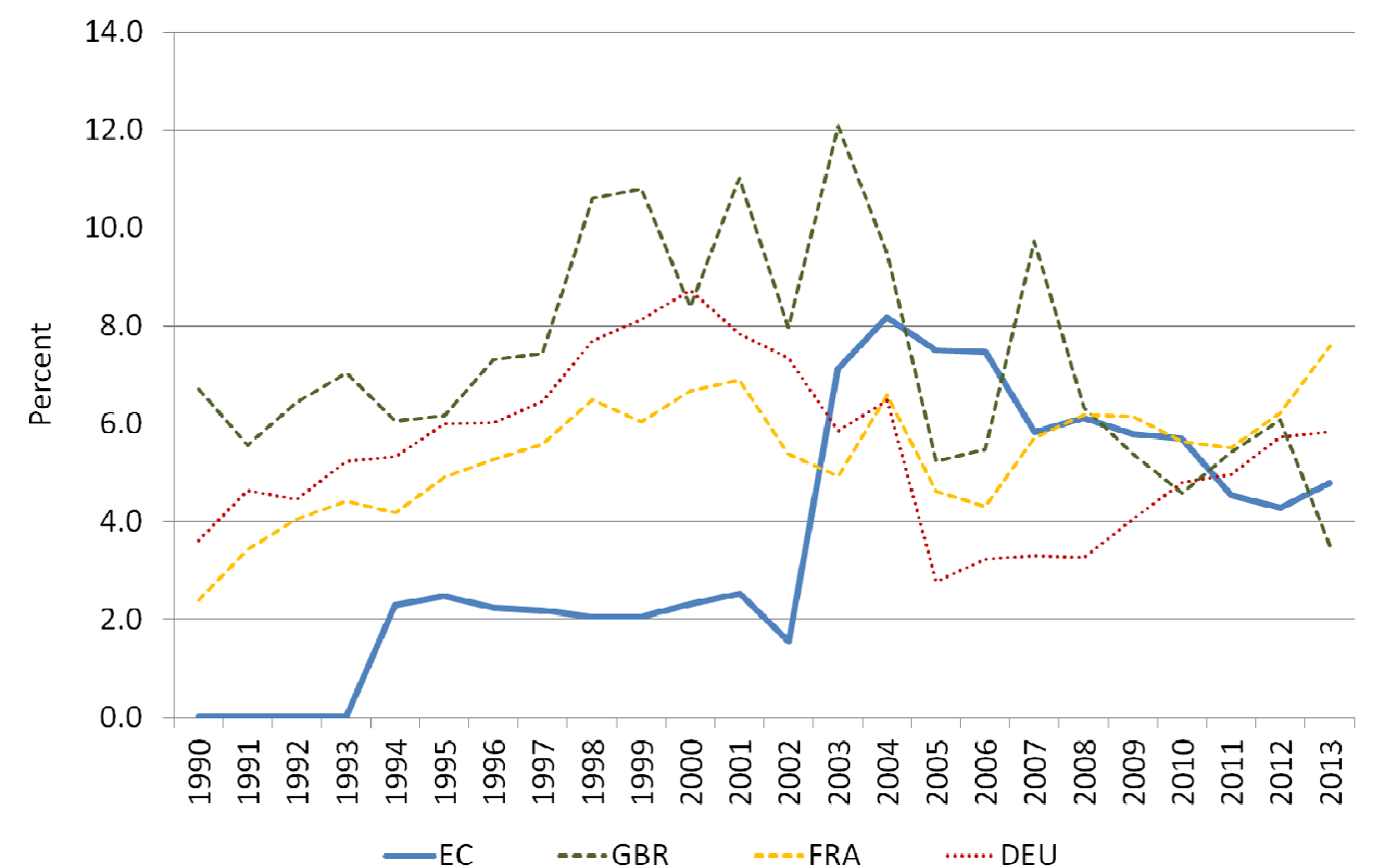

* Total bilateral aid includes pure bilateral aid and multi-bi aid, i.e., all aid except core multilateral. Source: OECD (2015).

These are not the type of capacity problems bureaucracies tend to underscore, but given the independent evidence, they seem to be the dominant ones. Some of our interviewees also conceded the knowledge and experience-based side of capacity limitations. One EuropeAid official stated, for instance, that while the EC has a global presence through its 141 country offices, they are primarily concerned with policy dialogue, and not with expert knowledge to supervise aid activities (I-27). The devolution of EC staff to the field further increased the perceived knowledge gaps (I-25). A World Bank official stated that the 'EC does not have enough experts available even in its neighbourhood countries' - in contrast to the World Bank (and other IDOs) that have a 'broad network of contacts on the ground needed for rapid implementation' (I-2). Recent studies have also revealed delays in the absorption of funds to support accession to the EU partly due to a lack of EC capacities (Mrak and Tilev, 2008; Knezevic, 2011). 
Given the recognition of its own capacity deficits, the EC tends to consider the delegation of aid to other institutions as efficient despite additional transaction costs. And it seems that among the different partners to whom EC staff can delegate its aid, IDOs are most highly valued. IDOs were identified as the 'most efficient alternative' for delegated aid (I-21). Due to unique expertise and their concrete mandate they have become the primary partner for EC officials. One EC official said that EC staff relied on IDOs 'when nobody else can do it' (I-30); another official explained that IDOs had an explicit mandate in some country contexts and hence nobody would work around them (I-21). One official also praised the flexibility implied by the partnerships with IDOs.

Overall, despite the additional transaction costs incurred, multi-bi aid may turn out to be efficient given current capacity constraints at the EC. Of course, the best solution - at least in the long run - is to lift the capacity constraint or to better manage existing capacities (OECD, 2012). This appears to be above all a matter of organizational management and skills development, since - as opposed to what staff interviews may suggest - current limitations seem to be primarily of a qualitative, rather than quantitative or financial nature.

\subsubsection{Member state politics}

As opposed to capacity concerns that drive the EC itself into soliciting arrangements with other IDOs, there appear to be situations where this move is more directly driven by member countries. As mentioned above, this happens primarily in the context of large multi-donor trust funds, namely the global funds. Global funds are legally independent multilateral institutions that address specific development sectors and that have their aid programs executed by IDOs through multi-bi aid (Heimans, 2004; Isenman and Schakow, 2010; Reinsberg et al., 2015a). Prominent examples of such funds with EU involvement are the Global Fund (to Fight Aids, Tuberculosis and Malaria), the Heavily Indebted Poor Countries (HIPC), the Consultative Group on International Agricultural Research (CGIAR), the Afghanistan Reconstruction Trust Fund (ARTF), or the Global Partnership on Education.

EU members participate in global funds in different ways. For example, only Germany, France and the United Kingdom are CGIAR council members, but the fund has 13 European donors including the EC (CGIAR, 2015). While the EC is not a council member in the CGIAR, it is a council member in the Global Fund, contributing about $4.5 \%$ of total resources (as compared to $0.7 \%$ for the CGIAR).

In some cases, both the EU and member states individually are represented in the respective fund governing boards. Arguably, this double-representation increases overall transaction costs and hence undermines economic efficiency. It also seems likely that EU member states adjust their own contribution to global funds to the contribution by the EC (I-25). This suggests that EU members do not coordinate on funding decisions (I-20; I-24). One official explicitly stated: 'This happens because there is not really any coordination between bilateral donors - even though they [i.e., the Member States] decide what the EU does' (I-20).

However, double-delegation implies tangible political benefits for all actors involved. These benefits counterbalance the potentially higher transaction costs (I-19). As one official put it, "[t]here is no economic rationale - but politically, it makes a lot of sense' (I-29). Similar views were expressed by 
officials of an important EU donor country (I-28). The EC itself has tangible benefits from its participation in global funds. An 'EU chair' enhances its visibility as an (independent) development actor. In addition, the EU believes that it can bring 'added value' to the practices of the Global Fund by insisting on strong fiduciary frameworks and strict monitoring (I-19). Within the EC, the economic and political advantages and disadvantages of participation are well reflected (I-19).

What is more, the member states (collectively) benefit from a distinctive EC contribution to global funds. Financially, EC contributions enable the member states to reduce their own contribution without losing policy influence and without violating the international burden-sharing commitment underlying most global funds (I-25). Politically, the EC's participation in global funds helps EU member states to demonstrate their commitment to a multilateral effort, even when they are unable to participate everywhere individually. This is particularly relevant for smaller member states. The 'EU chair' effectively gives them a possibility to 'free-ride' on the international attention to a high-profile development issue - an argument originally developed in the alliance literature (Olson and Zeckhauser, 1966; Sandler and Hartley, 2001; Addison et al., 2004). As global funds also include many non-EU donors, the EU as a whole benefits from a leverage effect of its participation. EC support may also be a 'seal of approval', serving as catalyst for such complementary contributions (I-22; I-25).

To influence decision making within the global funds, a distinct 'EU chair' may also be helpful. Given the large number of non-EU actors represented, a distinct EU perspective can be more easily advocated if both member states and the EC have a voice at the table. Moreover, pre-pooling funds at the European level gives even small EU member states some influence on relevant policies (I-24). ${ }^{9}$

Larger member states were also reported to be making strategic use of the EC's investment in global funds to increase the political weight of their own contribution (I-24). The member state already participating in the fund takes over the representation of the EC as a whole and thereby substantially increases its influence over funding decisions. This view in which the 'EU chair' primarily serves the interests of the big powers is reminiscent of the inter-governmentalist approach (Moravcsik, 1993). In this case, the visibility of the EC itself is rather limited.

Overall, the benefits from the EC's participation in global funds tend to be high for the member states, possibly higher than for the EC itself. This also holds if individual EU members enter a fund along with the EC, and the EC reinforces their interest while simultaneously representing the interests of the nonparticipating EU members. The EC thereby provides more weight to European positions. This may hence be perceived as an instance of well-working EU collective action.

\subsection{Why EC participation in trust funds is so burdensome}

Once the EC decides to participate in a trust fund, be it on its own initiative or at the initiative of individual member states, there seems to be an understanding that this cooperation will be beneficial. If so, why would the EC increase transaction cost for all actors involved and counteract the efficiency of this cooperation by its own exigencies? And why would the EC want to intrude into IDOs' implementation activities given that its own lack of capacity was one of the key reasons for delegation

9 Similar small-donor behaviour occurs in multi-donor budget support (see Faust et al., this issue). 
in the first place? Yet, virtually all IDO representatives we interviewed reported that cooperation with the EU institutions is excessively burdensome, and EC officials, when confronted with this statement, never denied that this corresponded to reality. What are the reasons for this behaviour?

The academic literature suggests that the burden for IDOs may be related to the intensity of earmarking associated with multi-bi aid since it limits the IDOs' discretion in aid allocation and imposes the bilateral donors' priorities (see, e.g., Sridhar and Woods, 2013; Reinsberg et al., 2015a). We hence examine the earmarking intensity of EU multi-bi aid as compared to multi-bi aid of other bilateral donors. The Eichenauer and Reinsberg (2016) dataset allows us to categorize multi-bi aid with respect to thematic, geographic and institutional earmarking, with three degrees of intensity for each category (no earmarking, soft earmarking and tight earmarking). For thematic earmarking, soft earmarking refers to specific sectors or fields of intervention, tight earmarking to specific projects. For geographic earmarking, soft earmarking includes (sub-)regional earmarking while tight earmarking refers to specific countries. For institutional earmarking, soft earmarking is a contribution to (sub-)division in the organization, while tight earmarking implies the delegation of staff for a concrete task. Many aid flows are earmarked on more than one dimension.

Figure 4 presents the available data for the period since 2006 when EU multi-bi aid became a nonnegligible quantity. The data show that, generally, institutional earmarking is negligible, while thematic and geographic earmarking is widely spread. Along these two dimensions, as compared to member countries, the EC has a somewhat stronger tendency to use earmarking, and to use tight rather than soft earmarking. This must be expected because the EC is less flexible in how it spends money due to the specific rules underlying its budget instruments. In relative terms, the greatest difference takes place for thematic earmarking where the EC pre-defines concrete projects about twice as often as the aid agencies of its member states. Nevertheless, this happens only for $13 \%$ of all multi-bi aid that the EC channels through other IDOs. It appears surprising that such relatively small shares (and even smaller absolute differences as compared to the earmarking intensity of individual member agencies) should have led IDO staff to complain so heavily about the burden of cooperating with EU institutions.

According to our interviewees, it seems to be the procedural and administrative requirements rather than the depth of earmarking that are considered the primary concern by IDO staff. World Bank officials state that dealing with the EU 'is a nightmare' involving cumbersome procedures and strict controls (I-1; I-6). In particular, Bank staff face separate audits from the EU, which require information at a level of detail that even the Bank itself sometimes cannot provide (I-8). To verify results, the EU also performs joint evaluation missions sponsored by the EU and must provide verification of results (I-3; I-4; I-13). One Bank official wondered about the 'schizophrenia' of the EU, which sometimes 'seems to forget its commitment to aid effectiveness when being obsessed with financial details' (I-10). All queried Bank staff complained about 'unprecedented levels of procedural controls', going well beyond the requirements of most other donor countries (I-8; I-18). 
Figure 4: The intensity of earmarking by EU institutions and member states (MS), 2006-2012

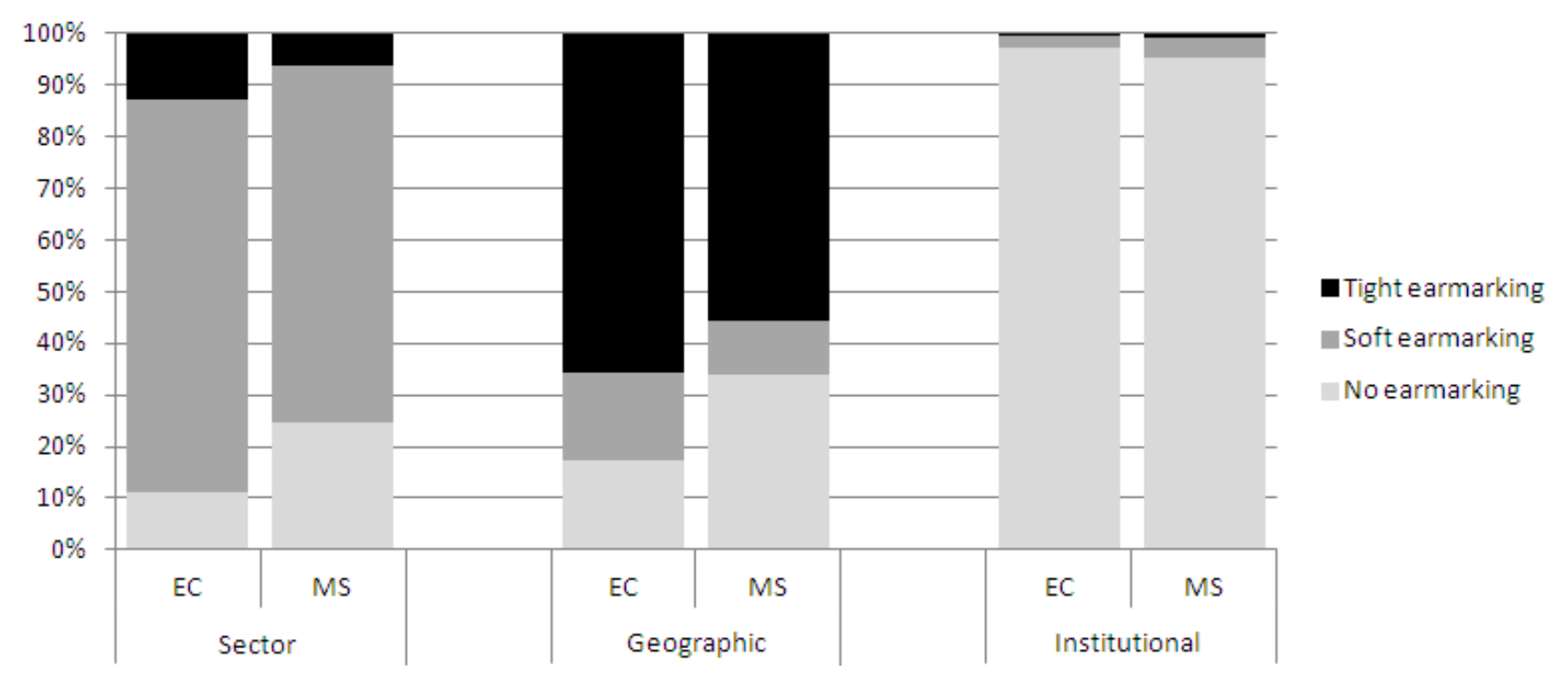

Note: Within each category, percentages refer to earmarked projects as a share of multi-bi aid. By definition, multi-bi aid is always earmarked in at least one category.

Source: Eichenauer and Reinsberg (2016).

These statements are again in line with findings from the DAC Peer Review. In the recommendations for organization and management the 2007 review already identified the need to simplify procedures, and the 2012 review considers that 'there is still a pressing need to simplify procedures further' (OECD, 2012: 113).

We also find some support in the Eichenauer and Reinsberg (2016) data that include separate codes for specific ancillary activities pursued through multi-bi aid (as far as these activities are reported in the qualitative project descriptions of the CRS database). Results presented in Figure 5 show that the EC more frequently contributes to evaluation and verification than the member states. For verification, the difference is particularly striking and clearly significant (t-statistic of 14.6), even if overall shares of aid activities for which any such activities have been reported, are quite small. In contrast to the EC's procedural rules, EU member states tend to focus their ancillary activity in areas that signal a more substantial interest, namely missions and conferences.

In sum, it appears that the EC earmarks its multi-bi aid somewhat more strongly than individual EU member states, but that the central reason for the burden it creates for IDOs are procedural requirements rather than the depth of earmarking. As this kind of 'micromanagement' (I-7; I-12) is of a more legal-administrative nature and does not require specific development expertise, it is not constrained by the limited development-related knowledge and experience of the EC staff. In fact, EC staff capacity in terms of legal and procedural knowledge (as opposed to substantive development knowledge) may even be relatively high. This can explain why we witness a delegation of aid to IDOs that is (at least partly) due to capacity constraints, while the EC staff simultaneously spends much time and effort on monitoring these activities. 
Figure 5: Ancillary activities financed by multi-bi aid, 2006-2012

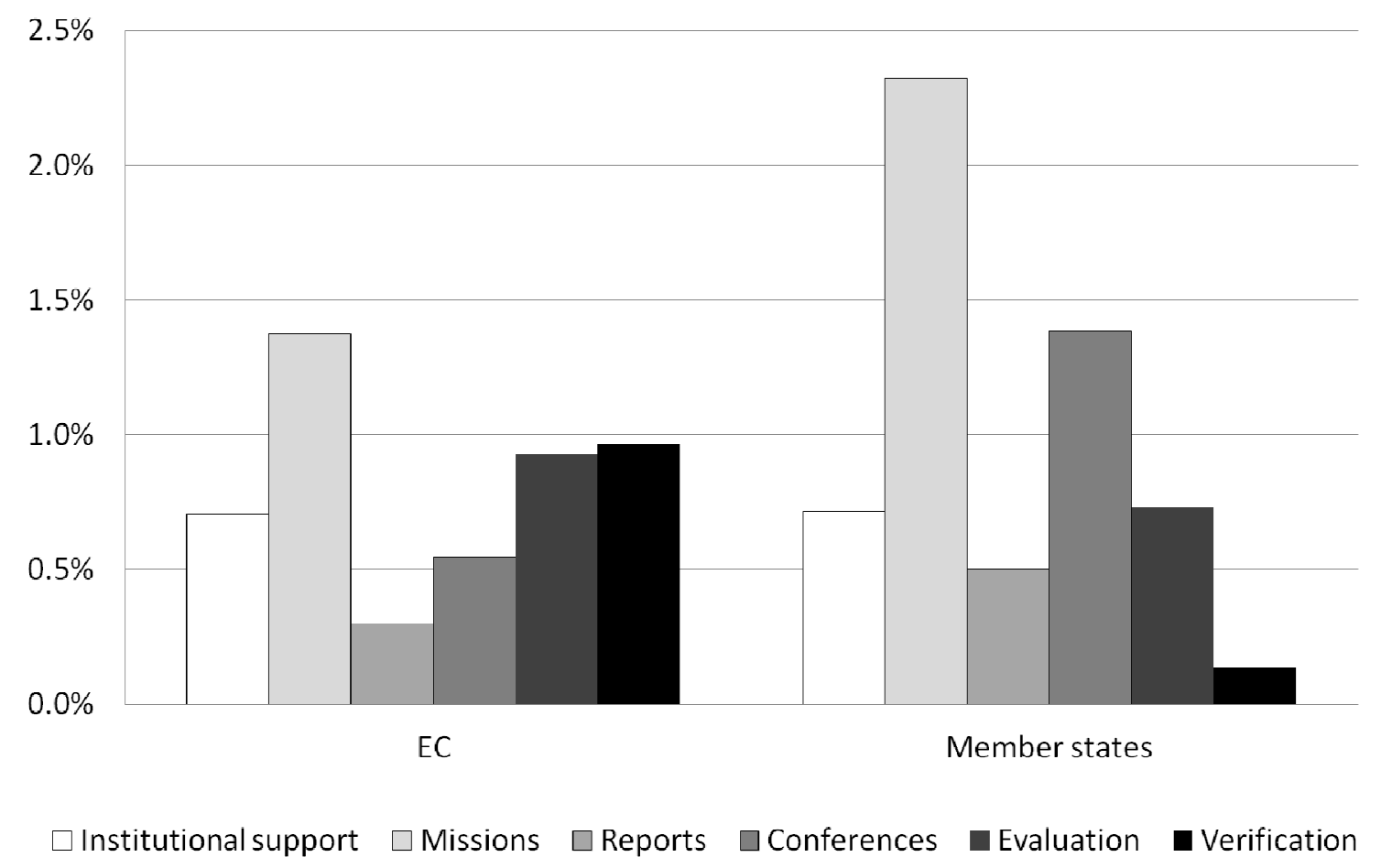

Notes: Percentages refer to the share of activities in the CRS database, for which the specific purpose was explicitly mentioned in the qualitative project description. This may underestimate the true shares, since such detailed reporting was not required. The different categories are not mutually exclusive as they can be funded within a single aid activity.

Source: Eichenauer and Reinsberg (2016).

An alternative explanation may be that the burden created for IDOs is not primarily due to the EC staff's own preferences, but imposed upon them by member countries and/or the European Parliament. Given their limited discretion regarding their financial contribution to the EC's development budget, strict accountability criteria imposed onto EC staff appear very plausible. Whether the EC implements projects directly or channels its contribution through other IDOs simply may not make a difference in this respect. According to EC officials, the Financial Regulation of the EU embodies the respective rules (I-6; I-20; I-29; I-30). In particular, the Financial Regulation stipulates that the EC reserves the 'right to verify the financial management of a specific action performed by the [IDO]' (EC, 2013: 18). The Financial Regulation also encourages the EC to conduct 'joint evaluation missions' and to 'perform evaluation missions as a donor' (EC, 2013: 17). The costs of these evaluations must be borne by the EU, but they are administratively burdensome to IDOs.

In some interviews, EC officials pointed to the fact that it is the finance ministers of the member states and the Court of Auditors that repeatedly tightened up the Financial Regulation requirements in this respect (I-24). At the same time, the European Parliament pressured for greater visibility of EC aid. In 2008 , it adopted a policy reform that set clear guidelines for ensuring the visibility of EC contributions 
under delegated cooperation (I-25). Against this background, EC officials are obliged to ensure the traceability of delegated funds (I-20; I-21; I-24). This sometimes forces EC officials into less efficient multi-bi aid instruments, for example single-donor trust funds, even if the underlying purpose is to support the effort of existing multi-donor trust funds (I-11; I-21; I-22). This is, indeed, reflected in a very high share of single-donor trust funds within the overall number of funds the EC participates in. For the period from 2006-12, this share was about 85\% (as compared to about 65\% for EU member states; see Eichenauer and Reinsberg, 2016). One official noted that the related rules sometimes ran counter to the members' expressed political will, and that they were also much stricter than their own national accountability rules. While the members' jointly decided accountability rules did not allow the EC to become member of the United Nations Central Emergency Response Fund (CERF) 'they do not need to account for CERF at home'. (I-19). Only the 2012 Financial Regulation somewhat loosened these constraints (I-24). Last, the European Parliament and the European Court of Auditors also force the EC to negotiate liability clauses to ensure refunds from IDOs in case EC resources are lost.

World Bank staff deplores that 'pressures [from influential donor countries] are scaled up at the European level', and that the EC 'is unable to liberate itself from its own accountability pressures' (I7). Especially when compared to the World Bank, 'the EC is governed by constraints rather than by incentives' (I-2; I-5). This again echoes concerns voiced repeatedly in DAC Peer Reviews:

The development co-operation programme is under high scrutiny from both Council and European Parliament. As was recommended in 2007, this oversight could be made more strategic and focus more on the expected results, beyond controlling inputs and outputs. Detailed scrutiny currently leads to micromanaging the programme and hampers its effective delivery in the field (delays, lack of flexibility to respond to emerging needs, time consuming procedures) (OECD, 2012: 111).

However, not all EC officials we interviewed considered these strict regulations as a constraint on their freedom of action. In fact, a significant part of EC officials consider these strict rules as a value added of the EC. According to one respondent, given that the EC does not have any vital substantive policy interest, it can credibly be the custodian of aid effectiveness by ensuring the proper use of funds (I-19).

Another official even directly objected to the proposition that complications were imposed by the member states: 'The EC is complicated because we want accountability' while 'we' referred explicitly to staff as opposed to the Member States." (I-24). Clearly, opinions in this respect varied between our respondents.

Outside the EU, there seems to be a broad consensus that procedural regulations are overly strong and inefficient. Some reforms towards greater flexibility have been carried out over time, but many problems remain. Among other things, EC staff seems to be more experienced in these administrative and legal procedures than in substantive areas of international development cooperation. Hence in terms of their own work management, delegating aid while retaining the monitoring tasks appears like a sensible strategy that matches their profile. In terms of overall aid effectiveness, this specialisation may, however, be problematic. 


\section{Conclusion}

Since the mid-2000s, the EC has become very active in the area of multi-bi aid. By doing so, it has followed, and even surpassed, the general trend by bilateral donors to channel their funds through IDOs. Given that the EU is already a multilateral institution that combines the resources of its member countries, its strong participation in trust funds at such IDOs seems like an inefficient doubledelegation strategy. However, given that the development-related capacity and expertise at the EC is scarce (while it is in ample supply at several specialised IDOs) from the EC's perspective, multi-bi aid can be rightly considered as a promising approach.

These IDOs, however, perceive the EC as a particularly burdensome donor. Its micromanagement is legendary $-\mathrm{a}$ fact that appears puzzling in light of its capacity constraints. Yet, these constraints relate to the appropriate deployment of development-related expertise while the EC's micromanagement focuses primarily on legal and administrative procedures (where capacity within the EC is much higher). In addition, some interviews suggest that this micromanagement is not a deliberate choice of EC staff, but the EC merely passes on the pressure for control from other EU actors, notably the European Parliament and the Court of Auditors.

Until recently, the EC's lack of own development expertise has also contributed to its lack of interest in setting up and administering its own trust funds. However, the gradual removal of important regulatory constraints following greater demand from member states, and increased interest by the EC itself in recent years has catalysed the creation of the first two Union Trust Funds in 2014.

Without going as far as other IDOs (which generates new problems of transparency, oversight and fragmentation), hosting a few trust funds may be an interesting way for the EC to implement its coordination function, not necessarily involving all members at a time. This may also help to solve potential collective action problems by giving more strongly engaged members a stronger voice and higher visibility. Moreover, this could move the focus from procedural aspects to subject-related ones, which could in turn be very helpful for the fruitful (and efficient) cooperation between the EU institutions and other IDOs. 


\section{References}

Addison, T., McGillivray, M. and Odedokun, M. (2004) Donor Funding of Multilateral Aid Agencies: Determining factors and revealed burden sharing. Helsinki: UNU-WIDER.

Barakat, S. (2009) 'The Failed Promise of Multi-Donor Trust Funds: Aid financing as an impediment to effective state-building in post-conflict contexts', Policy Studies 30(2): 107-26.

Barakat, S., Rzeszut, K. and Martin, N. (2012) What Is the Track Record of Multi-Donor Trust Funds in Improving Aid Effectiveness? An assessment of the available evidence. London: EPPI-Centre, Social Science Research Unit, Institute of Education, University of London.

Carbone, M. (2007). The European Union and International Development: The politics of foreign aid. Abingdon: Routledge.

CGIAR (2015) CGIAR Fund, http://www.cgiar.org/who-we-are/cgiar-fund/ (accessed 10 April 2015).

EC (2015). European Commission and Italy launch first ever EU Regional Trust Fund in response to the Syrian Crisis. Brussels, European Commission (Accessed 20 April 2015).

EC (2014). International cooperation and development. www.ec.europa.eu/europeaid (accessed 30 October 2015).

EC (2013). Frequently Asked Questions: International organizations. Brussels: European Commission.

EC (2012). First simplification scoreboard for the MFF 2014-2020, Brussels: European Commission. $\operatorname{COM}(2012) 531$ final.

EC (2007). Eu Code of Conduct on Division of Labour in Development Policy. Brussels: European Commission.

Eichenauer, V. and Reinsberg, B. (2014) Multi-Bi Aid: Tracking the evolution of earmarked funding to international development organizations from 1990 to 2012. CIS Working Paper No. 84. Zurich: Center for Comparative and International Studies.

Eichenauer, V. and Reinsberg, B. (2016) 'What Determines Earmarked Funding to International Development Organizations? Evidence from the new multi-bi aid dataset'. CIS Working Paper No. 88. Zurich: Center for Comparative and International Studies.

Graham, E.R. (2015) 'Money and Multilateralism: How funding rules constitute IO governance', International Theory 7(1): 162-94.

Heimans, J. (2004) Multiactor Global Funds: New tools to address urgent global problems. UNU/WIDER Research Paper No. 47. Helsinki: UNU-WIDER.

IEG (2011) An Evaluation of the World Bank's Trust Fund Portfolio: Trust fund support for development. Washington, DC: Independent Evaluation Group.

Isenman, P. and Shakow, A. (2010). Donor Schizophrenia and Aid Effectiveness: The role of global funds. IDS Practice Paper No. 5. Brighton: Institute of Development Studies.

Knezevic, I. (2011) Absorption Capacity of Serbia for Use of EU Funds: Practical lessons from Slovakia. Belgrade: The Pontis Foundation and the Center for Democracy Foundation.

Michaelowa, A. and Michaelowa, K. (2011) 'Climate Business for Poverty Reduction? The role of the World Bank', The Review of International Organizations 6(3-4): 259-86. 
Michaelowa, K., Reinsberg, B. and Schneider, C. (2015) 'When International Organizations Delegate: The politics of earmarking European Union aid to multilateral aid institutions', mimeo, University of Zurich and UC San Diego.

Milner, H.V. and Tingley, D. (2013) 'The Choice for Multilateralism: Foreign aid and American foreign policy', The Review of International Organizations 8(3): 313-41.

Moravcsik, A. (1993) 'Preferences and Power in the European Community: A liberal intergovernmentalist approach', Journal of Common Market Studies 31(4): 473-524.

Mrak, M. and Tilev, D. (2008) Absorption for EU Pre-Accession Funds: Concept and implications for Kosovo. Prishtina: Kosovar Civil Society Foundation.

OECD (2015). Total Flows by Donor, OECD.Stat, http://stats.oecd.org/ Index.aspx?datasetcode=TABLE1 (accessed 18 April 2015).

OECD (2012). European Union, DAC Peer Review 2012. Paris: Organisation for Economic Cooperation and Development.

Olson, M. and Zeckhauser, R. (1966) 'An Economic Theory of Alliances', Review of Economics and Statistics 48(3): 266-79.

Reinsberg, B. (2016) 'The Implications of Multi-Bi Financing for Multilateral Agencies: The example of the World Bank', in T. Mahn, M. Negre and S. Klingebiel (eds) The Fragmentation of Aid: Concepts, Measurements and Implications for Development Cooperation. Basingstoke: Palgrave Macmillan.

Reinsberg, B., Michaelowa, K. and Eichenauer, V. (2015a) 'The Rise of Multi-Bi Aid and the Proliferation of Trust Funds', in M. Arvin (ed.), The Handbook on the Economics of Foreign Aid. Cheltenham: Edward Elgar.

Reinsberg, B., Michaelowa, K. and Knack, S. (2015b) 'Which Donors, Which Funds? The choice of multilateral funds by bilateral donors at the World Bank'. Presented at IMF/CFD Conference, Geneva, April 15-17.

Sandler, T. and Hartley, K. (2001) 'Economics of Alliances: The lessons for collective action', Journal of Economic Literature 39(3): 869-96.

Schneider, C.J., and Tobin, J. (2013) 'Interest Coalitions and Multilateral Aid Allocation in the European Union', International Studies Quarterly 57(1): 103-14.

Sridhar, D. and Woods, N. (2013) 'Trojan Multilateralism: Global cooperation in health', Global Policy 4(4): 325-35.

Tortora, P. and Steensen, S. (2014) Making Earmarked Funding More Effective: Current practices and a way forward. Better Policies for Better Lives Report No. 1. Paris: Organisation for Economic Co-operation and Development.

Woods, N. (2005) 'The Shifting Politics of Foreign Aid', International Affairs 81(2): 393-409. 